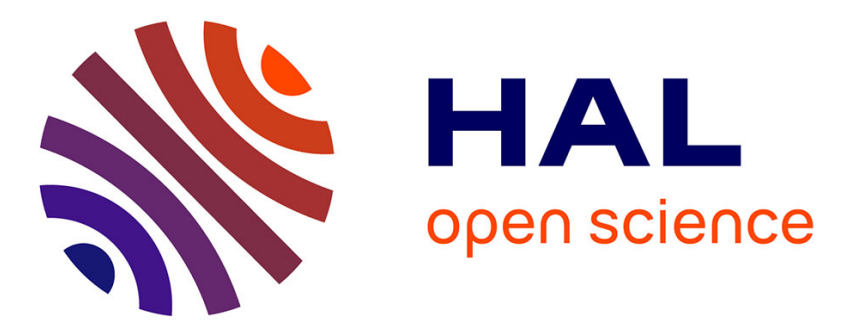

\title{
Revisiting the mechanism responsible for the light-struck flavor in white wines and Champagnes
}

Amaury Furet, Audrey Sicello, Bruno Guillemat, Christelle Absalon, Emilie Langleron, Dario Bassani

\section{- To cite this version:}

Amaury Furet, Audrey Sicello, Bruno Guillemat, Christelle Absalon, Emilie Langleron, et al.. Revisiting the mechanism responsible for the light-struck flavor in white wines and Champagnes. Food Chemistry, 2022, 372, pp.131281. 10.1016/j.foodchem.2021.131281 . hal-03411373

\section{HAL Id: hal-03411373 \\ https://hal.science/hal-03411373}

Submitted on 2 Nov 2021

HAL is a multi-disciplinary open access archive for the deposit and dissemination of scientific research documents, whether they are published or not. The documents may come from teaching and research institutions in France or abroad, or from public or private research centers.
L'archive ouverte pluridisciplinaire HAL, est destinée au dépôt et à la diffusion de documents scientifiques de niveau recherche, publiés ou non, émanant des établissements d'enseignement et de recherche français ou étrangers, des laboratoires publics ou privés. 
1 Revisiting the mechanism responsible for the light-struck flavor in white 2 wines and Champagnes

Amaury Furet, ${ }^{1}$ Audrey Sicello, ${ }^{1}$ Bruno Guillemat, ${ }^{2}$ Christelle Absalon, ${ }^{1}$ Emilie Langleron, ${ }^{3}$ Dario M. Bassani ${ }^{1}$ *

1. Univ. Bordeaux, CNRS UMR 5255, Inst. des Sciences Moléculaires, 351, Cours de la Libération, 33405 Talence, France. E-mail: dario.bassani@u-bordeaux.fr

2. Pernod-Ricard S.A., 5, cours Paul Ricard, 75008 Paris, France.

3. Martell, Mumm, Perrier-Jouët, 34, Rue du Champ de Mars, 51053 Reims, France

\section{Abstract}

The mechanism responsible for the appearance of the light-struck fault upon exposure of white wines and Champagnes to natural or artificial light is examined in light of new experiments involving methionine analogues. The latter show that the formation of volatile sulfur species upon irradiation of riboflavin in the presence of methionine in model wine solutions at $\mathrm{pH} 3$ is not dependent on the existence of neighboring group stabilization of the sulfur-centered cation radical through a 5- or 6-membered cyclic intermediate. Instead, the formation of a dimer radical cation is proposed in agreement with the formation of oxidation products such as dimethyldisulfide at early reaction times and the observed steric effect upon product distribution. The limiting quantum yield for the release of sulfur atoms from a solution of methionine in model wine solutions at $\mathrm{pH} 3$ containing riboflavin was found to be 0.26 (435 nm irradiation). No dependance of the quantum yield or product distribution on the irradiation wavelength was found over the range $365-490 \mathrm{~nm}$.

\section{Keywords}

Light-struck fault, riboflavin, methionine, sulfur, photooxidation

\section{Introduction}

The exposure of numerous foods and beverages to artificial or natural light results in undesirable changes in their organoleptic properties. In the case of white wines and Champagnes, this leads to an irreversible degradation commonly known as the light- or sunstruck fault that is characterized by changes in coloration and the smell of rotten eggs and cooked cabbage (Dozon \& Noble, 1989). Although the light-struck fault is a complex process whose chemical origins can differ between samples due to variations in grape composition and vinification techniques (Grant-Preece, Barril, Schmidtke, Scollary, \& Clark, 2017), the 
strongest off-odors such as those of rotten eggs and cooked cabbage are due to the generation of volatile sulfur species. Their formation has been linked to the photoinduced oxidation of sulfur-containing amino acids such as methionine (Met) and cysteine (Cys) by riboflavin (Rf) (Daniela Fracassetti, Limbo, Pellegrino, \& Tirelli, 2019; Mattivi, Monetti, Vrhovšek, Tonon, \& Andrés-Lacueva, 2000). The photoinduced oxidation of Met by $\mathbf{R f}$ is quite general, having also been evidenced in milk, dairy products, and beers (De Keukeleire, Heyerick, Huvaere, Skibsted, \& Andersen, 2008; Lee \& Min, 2009).

Riboflavin is a flavine co-factor and a well-known photocatalyst active the UV-visible region, absorbing light up to ca. $500 \mathrm{~nm}$ (Hering, Muhldorf, Wolf, \& Konig, 2016). Excitation of its isoalloxazine core leads to the population of an emissive $S_{1}$ excited state $\left(\Phi_{\mathrm{F}}=0.27\right)$ which is relatively short-lived due to efficient intersystem crossing to the triplet manifold ( $\tau_{\mathrm{S}}$ $\left.=5.1 \mathrm{~ns}, \Phi_{\mathrm{ISC}}=0.70\right)($ Daniel R. Cardoso, Olsen, \& Skibsted, 2007). The lifetime of the triplet state is much longer and can reach $\tau_{\mathrm{T}}=15 \mu \mathrm{s}$ in the absence of oxygen and selfquenching (D. R. Cardoso, Libardi, \& Skibsted, 2012). The long lifetime and high redox potential of ${ }^{3} \mathbf{R f}^{*}$ renders it particularly reactive towards food constituents such as phenolic species, peptides, purines, and lipids through either electron transfer or hydrogen abstraction reactions (D. R. Cardoso et al., 2012). In the case of Met, Huvaere et al. reported that the bimolecular quenching rate of ${ }^{3} \mathbf{R f}^{*}$ in water is sensitive to the $\mathrm{pH}$, with $k_{\mathrm{q}}=4.9 \times 10^{7} \mathrm{~s}^{-1}$ and $2.2 \times 10^{7} \mathrm{~s}^{-1}$ at $\mathrm{pH} 4.2$ and 7, respectively (Huvaere, Andersen, Storme, Van Bocxlaer, Skibsted, \& De Keukeleire, 2006). In contrast, Cys only quenches ${ }^{3} \mathbf{R f}^{*}$ efficiently under basic conditions as a result of deprotonation of the thiol group (Daniel R. Cardoso, Franco, Olsen, Andersen, \& Skibsted, 2004). The link between ${ }^{3} \mathbf{R f}^{*}$ and the formation of the light-struck fault is well established: Addition of $\mathbf{R f}$ enhances the light-struck fault in wines (Mattivi et al., 2000), whereas quenching of ${ }^{3} \mathbf{R f}^{*}$ was found to suppress the appearance of the light-struck fault in beers (Goldsmith, Rogers, Cabral, Ghiggino, \& Roddick, 2005) and wines (Daniela Fracassetti et al., 2019). Furthermore, the selective removal of $\mathbf{R f}$ has been recently proposed to be an effective strategy to improve the light-fastness of white wines (D. Fracassetti, Gabrielli, Encinas, Manara, Pellegrino, \& Tirelli, 2017).

Understanding the mechanism responsible for the light-struck fault sensitized by $\mathbf{R f}$ is essential in developing strategies for mitigating its effects and also in elucidating the formation of undesirable side-products. Surprisingly, few detailed mechanistic studies of the reaction between Rf* and Met or Cys have been reported. In the case of wines, the mechanism proposed by Maujean and Seguin in 1983 is widely accepted as accurately describing the formation of volatile sulfur-containing species $\mathrm{MeSH}$ and DMDS $\left(\mathrm{CH}_{3} \mathrm{~S}-\right.$ 
$\mathrm{SCH}_{3}$ ) upon irradiation of $\mathbf{R f}$ in the presence of Met or Cys (Maujean \& Seguin, 1983). The mechanism proposed bears resemblance to that previously put forth by F. A. Yang et al. in 1967, in which the formation of volatile sulfur products is also accompanied by the production of ethylene as evidenced using ${ }^{14} \mathrm{C}$-labelled Met (Huvaere et al., 2006; Yang, Ku, \& Pratt, 1967). In both mechanisms, the initial step involves oxidative electron transfer quenching of ${ }^{3} \mathbf{R f}^{*}$ by Met to generate a thiol-centered cation radical that undergoes subsequent decarboxylation and hydrolysis to give methional. The latter is also proposed to be an intermediate in the photooxidation of dairy products, although Silcock and co-workers later showed that it is formed competitively and not sequentially with MeSH (Asaduzzaman, Scampicchio, Biasioli, Bremer, \& Silcock, 2020).

Both the proposed intervention of the carboxylate anion and putative hydrogen atom transfer between two radical species suggest that this mechanism may not be able explain the efficient formation of the light-struck fault under the more acidic conditions found in white wines and Champagnes. We report here a detailed photochemical investigation which finds that the quantum yields for the formation of MeSH and DMDS are not dependent on the $\mathrm{pH}$. Furthermore, Met analogues in which either the carboxylate or ammonium fragment is removed exhibit identical efficiencies for the formation of MeSH and DMDS. Based on these results, an alternative mechanism involving the formation of a Met dimer cation radical is proposed. This mechanism explains the formation of both ethylene and DMDS under anaerobic conditions and is in agreement with the lack of $\mathrm{pH}$ dependence.

\section{Materials and Methods}

All commercially-available chemicals and solvents were of analytical or spectroscopic grade and used as received. Water was purified on a Milli-Q system immediately prior to use. Irradiations were carried out on an optical bench composed of a high pressure $200 \mathrm{~W} \mathrm{XeHg}$ lamp coupled to a high-efficiency monochromator. Solutions were placed in a 4-cm pathlength quartz cuvette to ensure complete absorption of light at all wavelengths. Model wine solutions were prepared by combining tartaric acid (3.5 g/ L), water and absolute ethanol $(88: 12 v / v)$ and adjusting the $\mathrm{pH}$ to 3.5 with $1 \mathrm{M} \mathrm{NaOH}$ solution. $\mathbf{R f}$ and Met were dissolved at the concentrations given below and the solutions deareated by purging with argon for 20 minutes when required.

Analysis of the irradiated solutions was conducted either by SPME-GC-MS (ThermoFinnigan Trace Ultra ISQ instrument equipped with an Optimax Wax Plus column) or using a SPME-GC-PFPD (Agilent 7890B instrument equipped with a DAB-WAX column and a 
105 PFPD 5383 detector from OI-Analytics). Sample injection was done using a carboxen106 polydimethylsiloxane (Carboxen-PDMS) SPME fiber (Supelco). For the quantitative analysis of methanethiol, DMDS and DMTS, calibration curves were obtained for each species using ethyldithioacetate (DTA) in ethanol as an internal standard (see SI). After irradiation, $9 \mathrm{~mL}$ of the irradiated solution was transferred to a $12-\mathrm{mL}$ dark glass vial and DTA was added ([DTA] $=1 \times 10^{-6} \mathrm{M}$ ). The sample was then sealed and allowed to rest for $15 \mathrm{~min}$ under moderate stirring, after which the SPME fiber was introduced into the solution for $15 \mathrm{~min}$ and then desorbed for 7 minutes into the injector of the $\mathrm{GC}$ at $250{ }^{\circ} \mathrm{C}$. The number of molecules of product was directly obtained by the quantitative analysis using the calibration curve for each sulfur species.

The number of photons absorbed was determined from the incident power assuming that all incident photons are absorbed. A mask delimiting the irradiation area was used to ensure that the photon flux remained constant during sample irradiation and measurement of the incident power. The incident power was measured before and after each irradiation using a calibrated powermeter (Thorlabs 100A equipped with a S170C sensor) thanks to the following equation:

$$
I=\frac{F e \times \lambda}{h \times c}
$$

Where $I$ is the number of incident photons per second, $F e$ the incident power (W), $\lambda$ the irradiation wavelength $(\mathrm{m}), h$ is Planck's constant $(\mathrm{Js})$, and $c$ the speed of light $(\mathrm{m} / \mathrm{s})$. The response of the power meter was checked at $365 \mathrm{~nm}$ against a ferrioxalate actinometer solution and found to deviate by $<5 \%$.

\section{Results and discussion}

The mechanisms proposed by Maujean and Seguin (Maujean et al., 1983) and by Yang et al. (Yang et al., 1967) share a common pathway leading to the formation of methional even though the latter was not detected by either group, reportedly owing to its instability under the reaction conditions. They then diverge in that Yang et al. propose a second PET reaction between ${ }^{3} \mathbf{R f}^{*}$ and methional, followed by elimination to form MeSH, ethylene, and formic acid. Formation of latter was confirmed by ${ }^{14} \mathrm{C}$-labbeled Met. Maujean and Seguin instead propose that methional undergoes either a retro-Michael addition reaction or hydrogen abstraction (Scheme 1). In both mechanisms, the MeSH that is produced may undergo autooxidation to form DMDS. In Scheme 1, bimolecular reactions between intermediates 
138 present at very low concentrations are highlighted in red. These include bimolecular reactions

139 between radicals, or between ${ }^{3} \mathbf{R f}^{*}$ and methional, whose concentration, if formed, was too 140 low to detect directly. Although plausible, mechanisms involving reactions between 141 ephemeral species are expected to be inefficient in fluid solutions. Furthermore, 142 intramolecular electron transfer from the carboxylate anion to the thiol-centered radical cation 143 (pseudo-Kolbe reaction) may be impeded under acidic conditions favoring protonation of the 144 carboxylate anion.

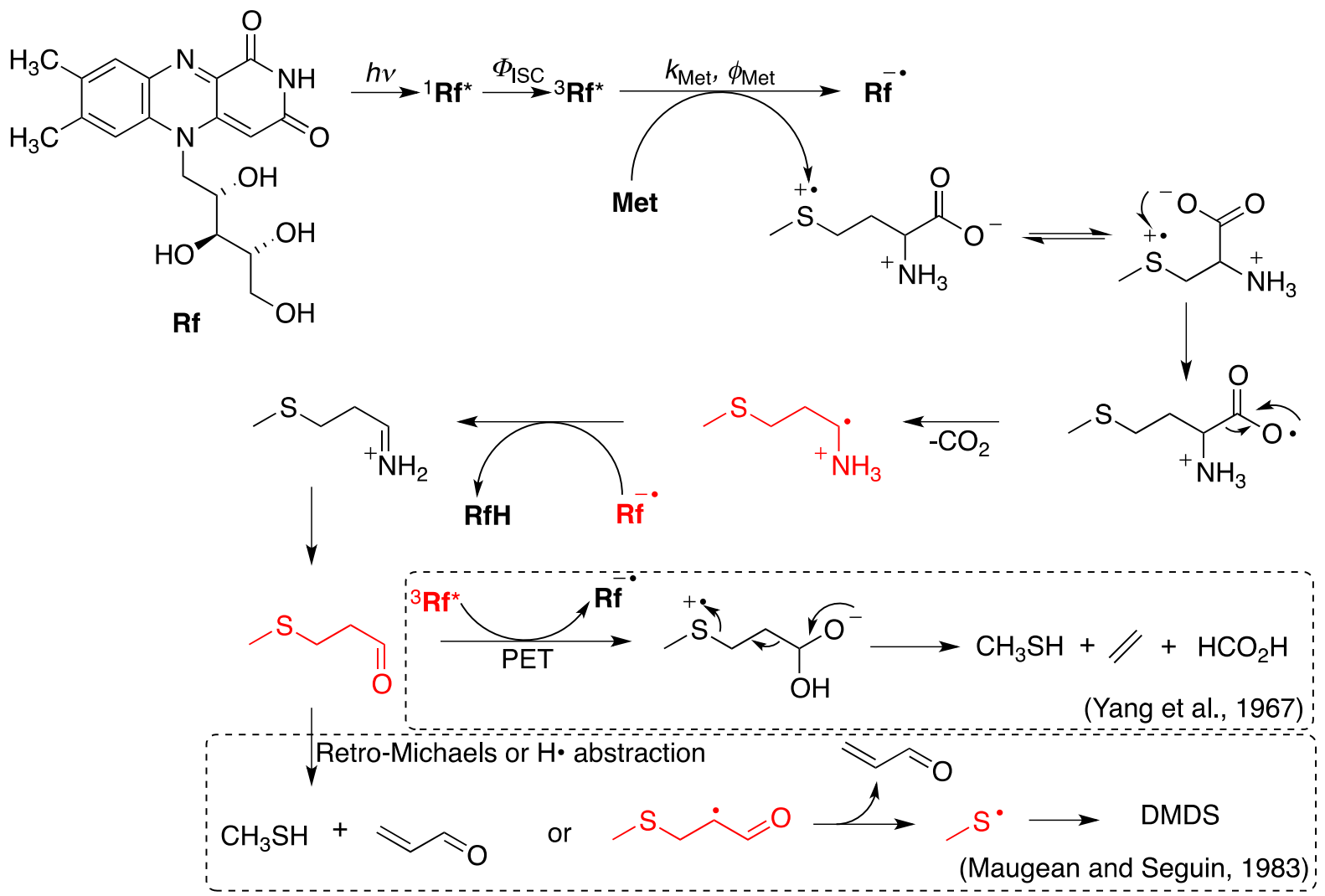

Scheme 1. Comparison of the mechanisms proposed by Maujean and Seguin (Maujean et al., 1983) and by Yang et al. (Yang et al., 1967) for the formation of volatile sulfur species upon irradiation of Rf solutions containing Met. Bimolecular reactions between intermediates present at very low concentrations are highlighted in red.

The mechanism in Scheme 1 involves the bimolecular reaction between ${ }^{3} \mathbf{R f}^{*}$ and Met.

152 Because of this, the quantum yield for the formation of volatile sulfur species, and hence the 153 impact of the light-struck flavor, will depend on the concentration of Met as has been 154 empirically observed previously. In a photochemical transformation, the quantum yield $(\Phi)$ 155 for the formation of a photoproduct is given by eq. 1 (Wagner, 1989):

$$
\Phi=\frac{\text { mols of product }}{\text { mols of excited states (photons absorbed) }}
$$


where the mols of product and photons are determined by SPME/GC/MS or PFPD and chemical or physical actinometry, respectively. Under our standard conditions ( $\mathrm{pH} 3.5)$, we found no dependance of the quantum yields upon the irradiation wavelength over the range $365-490 \mathrm{~nm}$ in agreement with the absence of participation of higher excited states over this wavelength range (see supplementary information). From mass spectral analysis of the irradiated solutions, we identify MeSH as the main photoproduct, accompanied by DMDS and dimethyltrisulfide (DMTS). The latter was also observed by Maujean and Seguin and attributed to subsequent oxidation of the primary photoproducts. (Maujean et al., 1983)

The quantum yield of each species as a function of Met concentration is shown in Figure 1A. Over the concentration range explored, $\mathrm{MeSH}$ is the major photoproduct formed with a quantum efficiency of $5.5 \%$ at $0.1 \mathrm{mM}$ [Met] (corresponding to $15 \mathrm{mg} / \mathrm{L}$ ). The efficiency of MeSH formation is quite significant given the ambient solar flux over the wavelength range that $\mathbf{R f}$ absorbs and, combined with the low perception threshold for sulfurcontaining volatiles, explains the high sensitivity of Champagnes and white wines rich in Met and $\mathbf{R f}$ towards the light-struck fault. Clearly, increasing the concentration of Met results in greater quantum efficiency for the formation of all three species since a greater proportion of

$173{ }^{3} \mathbf{R f}^{*}$ is intercepted by Met before deactivating through other channels. It is possible to 174 determine the limiting quantum yield for the oxidation of Met by excited Rf through a 175 double-reciprocal plot of $\Phi_{\mathrm{S}(\mathrm{Tot})}{ }^{-1}$ vs. [Met $]^{-1}$, where $\Phi_{\mathrm{S}(\mathrm{Tot})}=\Phi_{\mathrm{MeSH}}+2 \cdot \Phi_{\mathrm{DMDS}}+3 \bullet \Phi_{\mathrm{DMTS}}$ 176 and represents the total atom equiv. of sulfur released from Met per photon absorbed.(Wagner, 1989) As shown in Figure 1B, this plot is linear with an intercept of 3.90 corresponding to $\Phi_{\text {STot }}(\infty)=0.26$. Thus, at infinite Met concentration, roughly one fourth of all photons absorbed will lead to the liberation of a sulfur atom from Met. Correcting for the efficiency of

180 formation of ${ }^{3} \mathbf{R f}^{*},(70 \%)$, one finds that the intrinsic efficiency of the reaction between the 181 excited riboflavin triplet state and ${ }^{3} \mathbf{R} f *$ can reach $\phi_{\text {Met }}=0.37$. The slope of the doublereciprocal plot gives $\left(\phi_{\mathrm{Met}} k_{\mathrm{Met}} \tau_{\mathrm{T}}\right)^{-1}$, from which a value of $k_{\mathrm{Met}}=1.5 \times 10^{8} \mathrm{~L} \cdot \mathrm{mol}^{-1} \mathrm{~s}^{-1}$ can be

183 determined. This value is somewhat higher than that determined using laser flash photolysis at 184 a less acidic pH (Draper \& Ingraham, 1968). 

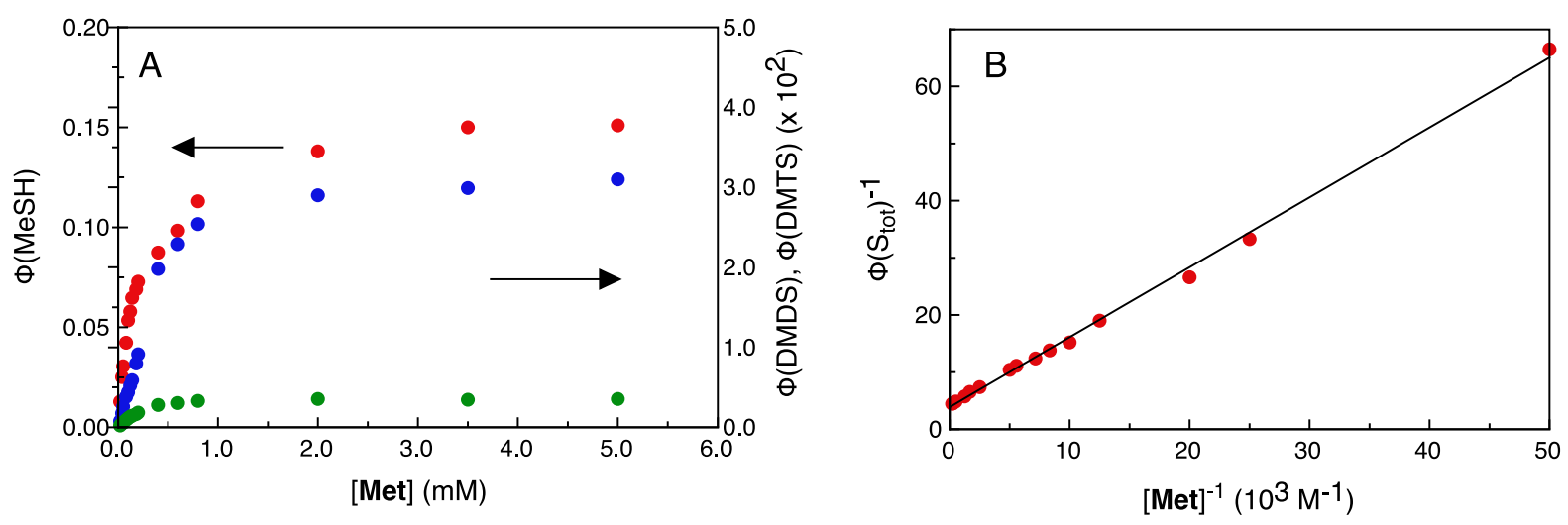

186

187

188

189

190

191

192

193

194

195

196

197

198

199

200

201

202

203

204

Figure 1. (A) Quantum yields for the formation of MeSH (red circles) DMDS (blue circles, and DMTS (green circles) upon irradiation of deaerated solutions of $\mathbf{R f}$ at $\mathrm{pH} 3.5$ vs. Met concentration $\left(\lambda_{\text {irr }}=435 \mathrm{~nm}\right)$. (B) Double-reciprocal plot of the total sulfur equiv. from the data in (A). Line is best fit according to $\Phi_{\mathrm{S}(\mathrm{Tot})}{ }^{-1}=0.0012[\mathrm{Met}]^{-1}+3.90$ with $r^{2}=0.998$.

To test the mechanism presented in Scheme 1, we proceeded to follow the quantum yield for formation of volatile sulfur species as a function of the $\mathrm{pH}$ of the solution. We can expect that under acidic conditions, when the carboxylate fragment in Met is protonated $(\mathrm{pH}$ $\leq 2.2$ ) (Vcelakova, Zuskova, Kenndler, \& Gas, 2004), the pseudo-Kolbe fragmentation will be inefficient and formation of the volatile sulfides impeded. Conversely, the fragmentation should be facilitated at basic $\mathrm{pH}$. The results obtained at various $\mathrm{pH}$ (Table 1), clearly indicate that while there is some $\mathrm{pH}$ dependence on the relative yields of MeSH, DMDS, and DMTS, the yield for that total atom-equivalents of sulfur $\left(\Phi_{\mathrm{S}(\mathrm{Tot})}\right)$ that is formed remains relatively constant. Even at $\mathrm{pH}<2$, where Met is predominately in its cationic form, there is no significant decrease in $\Phi_{\mathrm{S}(\mathrm{Tot})}$.

Table 1. Quantum yields ${ }^{\text {a }}$ for the formation of volatile sulfur species upon irradiation of model solutions. ${ }^{\mathrm{b}}$

\begin{tabular}{lllll}
\hline $\mathrm{pH}$ & $\Phi_{\mathrm{MeSH}}$ & $\Phi_{\mathrm{DMDS}}$ & $\Phi_{\text {DMTS }}$ & $\Phi_{\mathrm{S}(\mathrm{Tot})}$ \\
\hline 1.4 & 0.025 & 0.011 & 0.024 & 0.119 \\
3.0 & 0.037 & 0.025 & 0.022 & 0.153 \\
4.0 & 0.067 & 0.024 & 0.020 & 0.174 \\
5.0 & 0.062 & 0.017 & 0.021 & 0.160 \\
7.0 & 0.037 & 0.011 & 0.022 & 0.125 \\
8.9 & 0.016 & 0.011 & 0.023 & 0.106 \\
\hline
\end{tabular}


${ }^{\mathrm{a}} \pm 15 \%$. ${ }^{\mathrm{b}}$ Solutions were purged with Ar and irradiated at $435 \mathrm{~nm}(15 \mathrm{~min}),[$ Met $]=0.1 \mathrm{mM}$, $206[\mathbf{R f}]=50 \mu \mathrm{M}$.

The absence of significant $\mathrm{pH}$ dependance of the yield of the volatile sulfur species suggests that the intervention of the amino or the carboxylate fragments in the mechanism leading to their formation is not essential. This can be independently verified by comparing the product distribution and quantum yield for Met analogues in which either the carboxylate 212 or the ammonium fragment is absent. The results for this study are collected in Table 2 for 213 Met, 3-methylthiopropylamine, and 3-thiomethylbutanoic acid. The latter was prepared 214 through the ring-opening reaction of sodium methylthiolate onto $\gamma$-butyrolactone as described 215 previously (Zhou, Lu, Wang, Borhan, \& Reid, 2010). Within experimental error, we see only 216 small differences in the yield or product distribution of $\mathrm{MeSH}$, DMDS or DMTS, in 217 agreement with the absence of participation by either functional group. This result is in direct 218 contradiction with the radical-fragmentation induced decarboxylation involving a sixmembered transition state leading to the formation of $\alpha$-aminoalkyl radical. The subsequent formation of an imine intermediate and its hydrolysis to methional also appears unlikely on the basis of the photolysis of solutions containing 3-thiomethylbutyric acid. Furthermore, we observed that DMDS is formed even at short irradiation times in degassed solutions, suggesting that a different reaction pathway other than autooxidation of MeSH exists. Together, these results lead us to believe that an alternative mechanism may contribute to the formation of the light-struck fault.

Table 2. Structural effects on the formation quantum yield of volatile sulfur species. ${ }^{\text {a }}$

\begin{tabular}{|c|c|c|c|c|c|}
\hline Substrate & $\mathrm{pH}$ & $\Phi_{\mathrm{MeSH}}$ & $\Phi_{\mathrm{DMDS}}$ & $\Phi_{\text {DMTS }}$ & $\Phi_{\mathrm{S}(\mathrm{Tot})}$ \\
\hline & 3.5 & 0.104 & $6.37 \times 10^{-3}$ & $1.18 \times 10^{-3}$ & 0.12 \\
\hline & 3.5 & 0.094 & $4.36 \times 10^{-3}$ & $1.04 \times 10^{-3}$ & 0.11 \\
\hline & 5.6 & 0.071 & $3.92 \times 10^{-3}$ & $0.89 \times 10^{-3}$ & 0.08 \\
\hline
\end{tabular}

${ }^{\mathrm{a}}$ Error $= \pm 15 \%$. Solutions were purged with Ar and irradiated at $435 \mathrm{~nm}(15 \mathrm{~min})$,

229 Concentrations of substrate $=0.1 \mathrm{mM},[\mathbf{R f}]=250 \mu \mathrm{M}$.

The oxidation site in Met is understood to be located on the sulfur atom as it possesses 232 the lowest ionization potential (Naito, Kominami, Akasaka, \& Hatano, 1977; Reynaud, 
233 Malfoy, \& Canesson, 1980). In solution, sulfur-centered cation radicals can be stabilized 234 through formation of a three electron bond with Lewis base sites in the solvent or other 235 solutes, or intramolecularly with neighboring groups (Hendon, Carbery, \& Walsh, 2014). In 236 the case of $\mathbf{M e t}^{\mathbf{t}^{+}}$, transient absorption spectroscopy identified the formation of a dimer cation 237 radical at low $\mathrm{pH}$, whereas at more basic $\mathrm{pH}$ values, a 5-membered cyclic intermediate with 238 an $\mathrm{S} \therefore \mathrm{N}$ bond was proposed (Scheme 2) (Bobrowski, Hug, Marciniak, \& Kozubek, 1994). 239 The formation of other intermediates is nicely reviewed by Forbes and co-workers in their 240 elegant report on the use of time-resolved EPR experiments to elucidate the complex behavior

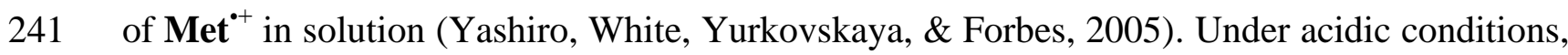
242 these authors find that the formation of the dimer cation radical is favored due to protonation 243 of the amino group. Therefore, we may expect that under the more acidic conditions of 244 photolysis present in white wines and Champagnes, the formation of $(\mathbf{M e t})_{2}{ }^{{ }^{+}}$may be 245 plausible. To evaluate this, the equilibrium constant $K_{\text {Dim }}$ can be estimated from the rates for 246 the formation and the dissociation of the dimer cation radical. These were determined in 247 aqueous solutions for various dialklylsulfides by Asmus and co-workers using pulse248 radiolysis, who found them to be very sensitive to steric repulsion (Chaudhri, Mohan, Anklam, $249 \&$ Asmus, 1996). In the case of dimethylsulfide, a value of $K_{\text {Dim }}=20$ is calculated at $0.1 \mathrm{mM}$. 250 For the heterodimer between $\mathrm{Me}_{2} \mathrm{~S}^{\bullet+}$ and $\mathrm{Et}_{2} \mathrm{~S}$, a value of $K_{\text {Dim }}=3.5$ is found instead. We may 251 expect that the dimerization constant for Met would lie in-between these two values, 252 indicating that its formation is thermodynamically favored under the experimental conditions 253 found in white wines and Champagnes. 


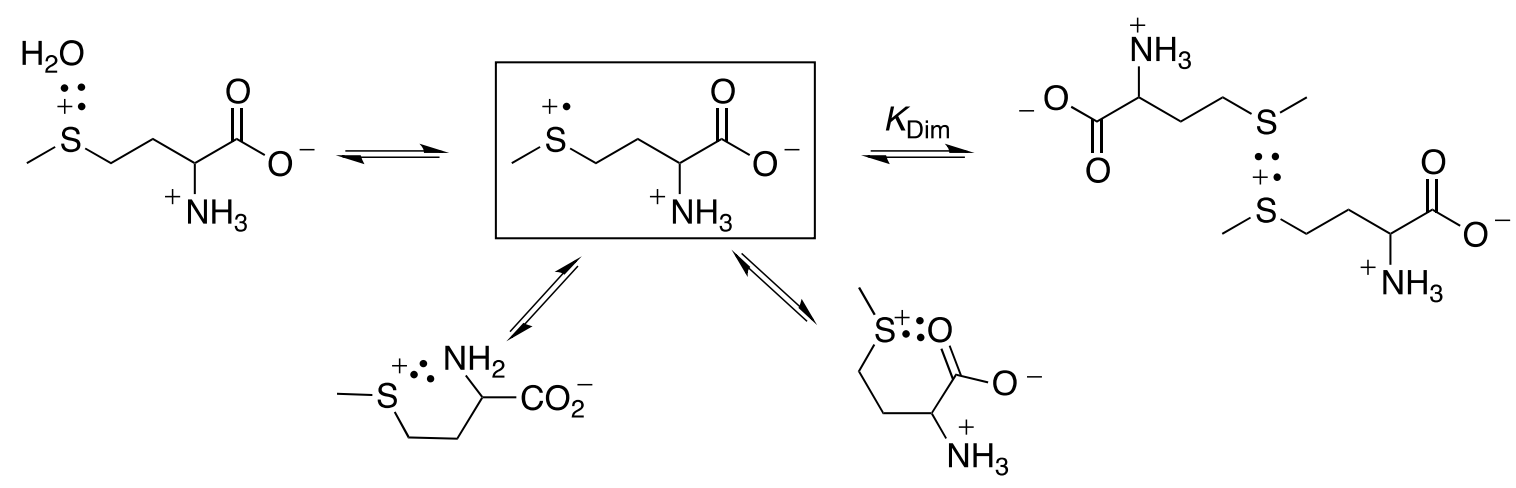<smiles>CSCC[C@H](N)C(=O)[O-]</smiles><smiles>C=C[C@H](N)C(=O)[O-]</smiles><smiles>C=CC(=O)C([NH3+])[CH+]C(=O)OC</smiles>

255 Scheme 2. Above: Stabilization of thioether cation radical in solution through a three-electron 256 bond with solvent $\left(\mathrm{H}_{2} \mathrm{O}\right)$, neighboring group, or intermolecularly through formation of a dimer cation radical. Below: Proposed mechanistic pathways for the formation of volatile sulfur species upon irradiation of $\mathbf{R f}$ in the presence of Met through either unimolecular $\beta$ deprotonation to yield MeSH (in blue) or through a dimer cation radical to give DMDS, ethylene, vinylglycine, and a glycine radical (in red).

The formation of a Met dimer cation radical may impact the formation of volatile sulfur species by allowing alternative fragmentation pathways. Thus, as shown in Scheme 2, deprotonationation at the $\beta$ position would lead to the elimination of vinylglycine. The ensuing S-centered radical can then undergo $\beta$-fragmentation to release DMDS, ethylene, and a stable glycine radical. Interestingly, this mechanism leads to the direct formation of DMSD without the need for oxidation of $\mathrm{MeSH}$ and could explain its formation at short irradiation times even in the absence of oxygen as observed above. The formation of ethylene as a byproduct of Met oxidation was previously observed and provides indirect support for this 
mechanism (Lieberman, Kunishi, Mapson, \& Wardale, 1965; Yang et al., 1967). Additionally, we have observed the formation of glycine by GC / MS (see supplementary information) during the irradiation of model wine solutions containing $\mathbf{R f}(250 \mu \mathrm{M})$ and Met $(0.1 \mathrm{mM})$.

To further probe the possible intermediacy of the $(\mathbf{M e t})_{2}{ }^{++}$in the direct formation of DMDS, we proceeded to compare the distribution of unsymmetrical disulfides that are formed when Met and its isopropyl analogue (IPM) are irradiated under identical conditions (Scheme 3). According to the effect of steric encumbrance on the formation of the sulfur-centered dimer cation radical, we would expect the formation of the mixed (Met $\therefore$ IPM) ${ }^{\bullet+}$ species to be unfavored. Indeed, the value of $K_{\text {Dim }}$ estimated from the formation and dissociation kinetics at $0.1 \mathrm{mM}$ is less than unity ( $K_{\text {Dim }}=0.8$ for $\mathrm{Me}_{2} \mathrm{~S}$ and $i \operatorname{Pr}_{2} \mathrm{~S}$ ) (Chaudhri et al., 1996). Because of this, disulfide formation should be biased towards the less sterically-hindered disulfide if it follows from the dimer cation radical. In contrast, free radical recombination is known to be less sensitive to steric hindrance and we may expect a more statistical distribution of disulfides to be formed. The irradiation of IPM solutions in the presence of $\mathbf{R f}$ under the same conditions as for Met results in the sole formation of isopropyl thiol, with diisopropyldisulfide appearing only at high conversions. This is in agreement with the inhibited formation of the dimer cation radical intermediate for IPM due to steric interactions. In a competition assay in which equimolar concentrations of Met and IPM (0.5 mM each) were irradiated in the presence of Rf, we only observe the formation of DMDS (96\%), with only $4 \%$ of mixed disulfide and no diisopropyldisulfide (DPDS) formed (Scheme 3). In fact, even employing a 25-fold excess of IPM to over-compensate for its 10-fold lower reactivity towards $\mathbf{R f}^{*}$ (see supplementary information), the ratio of DMDS : MPDS : DPDS is only of $71: 26: 3$. In contrast, a control experiment in which equimolar concentrations of the thiomethyl- and thioisopropyl- radicals were thermally generated in solution through hydrogen abstraction using a radical initiator (AIBN) evidenced the preferential formation of the mixed and diisopropyl disulfides (37\% and 61\%, respectively). This confirms that free radical dimerization of the alkylsulfur radicals is not overly sensitive to steric hindrance and that disulfide formation during irradiations does not follow this route. The bias towards formation of MPDS and DPDS over DMDS may reflect differences in stability between the radical species. 

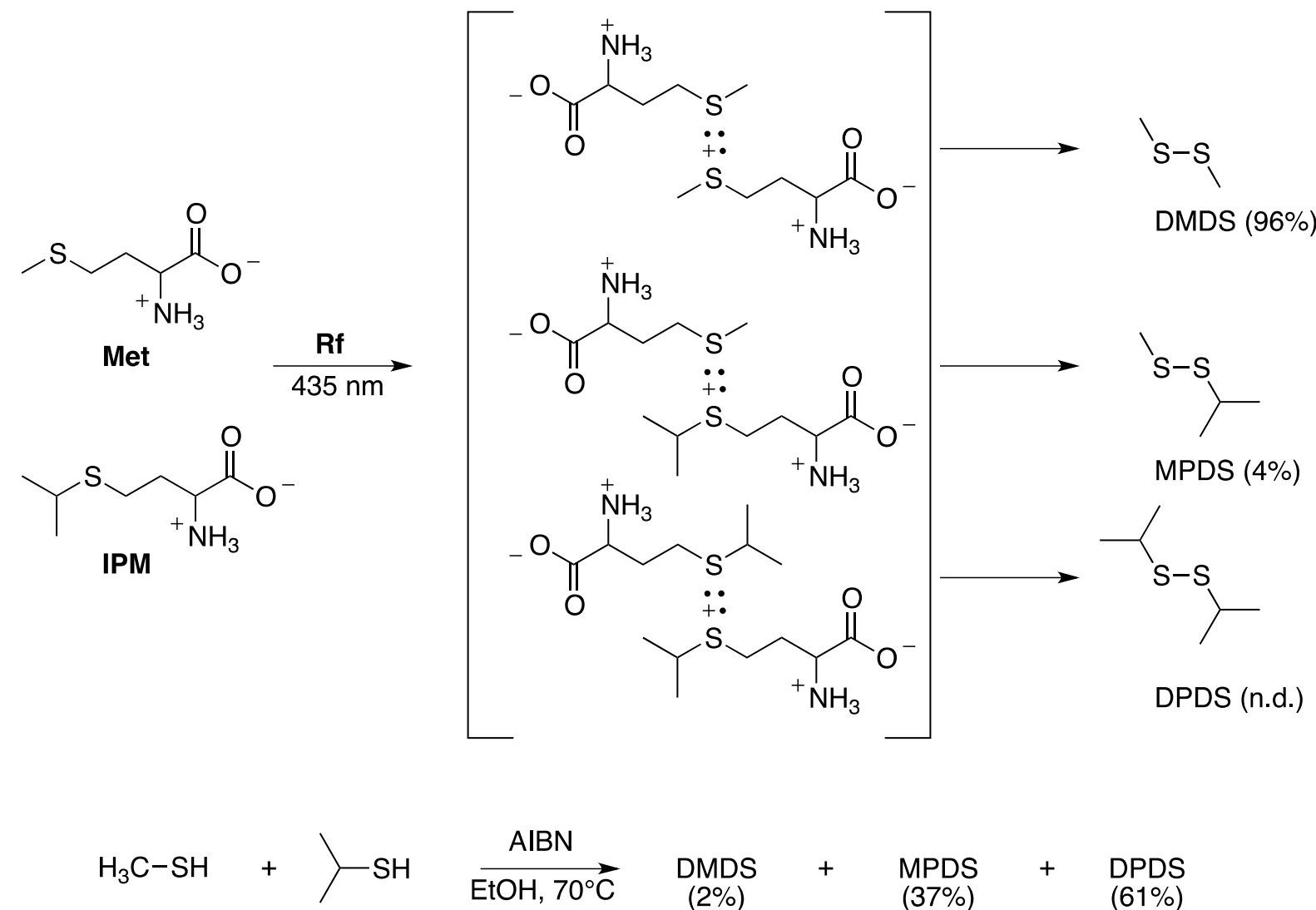

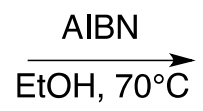
$\underset{(2 \%)}{\operatorname{DMD}}$ MPDS $(37 \%)$

DPDS

$(61 \%)$

Scheme 3. Competition experiment between Met and IMP with proposed intermediacy of thioether dimer cation radical formation.

\section{Conclusion}

The mechanism responsible for the light-struck fault in white wines and Champagnes was found to be extremely efficient as determined from the limiting quantum yield for sulfur atom equivalent liberated per photon absorbed (26\%), corresponding to 37\% from riboflavin triplet excited states. Thus, even at low Met concentrations $(0.1 \mathrm{mM})$, the quantum yield for the formation of $\mathrm{CH}_{3} \mathrm{SH}$ and DMDS are high (5\% and 0.4\%, respectively). Our results do not evidence a strong dependance of the quantum yields of product formation and their distribution on the $\mathrm{pH}$ or excitation wavelength. This suggests that neighboring group effects are small, in agreement with results from mechanistic studies using Met analogues. From this, we deduce that the formation of a dimer cation radical species may explain the formation of DMDS at short reaction times and in the absence of an oxidizing species such as molecular oxygen. The greater stabilization of a dimer cation radical may offer interesting approaches towards preventing or mitigating the formation of volatile sulfur species responsible for the 
320 Financial support from the ANR through grant ANR-17-CE07-0043-01, the Conseil Regional

Nouvelle Aquitaine (project 2018-1R20305), the Univ. of Bordeaux, and the CNRS is

gratefully acknowledged. We are also grateful to the CESAMO analytical facilities of the

Univ. of Bordeaux for their assistance.

\section{References}

Asaduzzaman, M., Scampicchio, M., Biasioli, F., Bremer, P. J., \& Silcock, P. (2020). Methanethiol formation during the photochemical oxidation of methionine-riboflavin system. Flavour Frag. J., 35(1), 34-41. https://doi.org/https://doi.org/10.1002/ffj.3536.

Bobrowski, K., Hug, G. L., Marciniak, B., \& Kozubek, H. (1994). The 4carboxybenzophenone-sensitized photooxidation of sulfur-containing amino acids in alkaline aqueous solutions. Secondary photoreactions kinetics. J. Phys. Chem., 98(2), 537-544. https://doi.org/10.1021/j100053a031.

Cardoso, D. R., Franco, D. W., Olsen, K., Andersen, M. L., \& Skibsted, L. H. (2004). Reactivity of Bovine Whey Proteins, Peptides, and Amino Acids toward Triplet Riboflavin as Studied by Laser Flash Photolysis. J. Agr. Food Chem., 52(21), 66026606. https://doi.org/10.1021/jf0401165.

Cardoso, D. R., Libardi, S. H., \& Skibsted, L. H. (2012). Riboflavin as a photosensitizer. Effects on human health and food quality. Food Funct., 3(5), 487-502. https://doi.org/10.1039/c2fo10246c.

Cardoso, D. R., Olsen, K., \& Skibsted, L. H. (2007). Mechanism of Deactivation of TripletExcited Riboflavin by Ascorbate, Carotenoids, and Tocopherols in Homogeneous and Heterogeneous Aqueous Food Model Systems. J. Agr. Food Chem., 55(15), 62856291. https://doi.org/10.1021/jf063497q.

Chaudhri, S. A., Mohan, H., Anklam, E., \& Asmus, K.-D. (1996). Three-electron bonded $\sigma / \sigma^{*}$ radical cations from mixedly substituted dialkyl sulfides in aqueous solution studied by pulse radiolysis. J. Chem. Soc. Perk. Trans. 2(3), 383-390. https://doi.org/10.1039/P29960000383.

De Keukeleire, D., Heyerick, A., Huvaere, K., Skibsted, L. H., \& Andersen, M. L. (2008). Beer lightstruck flavor: The full story. Cerevisia, 33(3), 133-144.

Dozon, N. M., \& Noble, A. C. (1989). Sensory study of the effect of fluorescent light on a sparkling wine and its base wine., $v .40$.

Draper, R. D., \& Ingraham, L. L. (1968). A potentiometric study of the flavin semiquinone equilibrium. Arch. Biochem. Biophys., 125(3), 802-808. https://doi.org/http://dx.doi.org/10.1016/0003-9861(68)90517-1.

Fracassetti, D., Gabrielli, M., Encinas, J., Manara, M., Pellegrino, I., \& Tirelli, A. (2017). Approaches to prevent the light-struck taste in white wine. Aust. J. Grape Wine Res., 23(3), 329-333. https://doi.org/10.1111/ajgw.12295.

Fracassetti, D., Limbo, S., Pellegrino, L., \& Tirelli, A. (2019). Light-induced reactions of methionine and riboflavin in model wine: Effects of hydrolysable tannins and sulfur dioxide. Food Chem., 298, 124952. https://doi.org/10.1016/j.foodchem.2019.124952.

Goldsmith, M. R., Rogers, P. J., Cabral, N. M., Ghiggino, K. P., \& Roddick, F. A. (2005). Riboflavin triplet quenchers inhibit lightstruck flavor formation in beer. J. Am. Soc. Brew. Chem., 63(4), 177-184. https://doi.org/10.1094/ASBCJ-63-0177.

Grant-Preece, P., Barril, C., Schmidtke, L. M., Scollary, G. R., \& Clark, A. C. (2017). Lightinduced changes in bottled white wine and underlying photochemical mechanisms. 
Crit. Rev. Food Sci. Nutr., 57(4), 743-754.

https://doi.org/10.1080/10408398.2014.919246.

Hendon, C. H., Carbery, D. R., \& Walsh, A. (2014). Three-electron two-centred bonds and the stabilisation of cationic sulfur radicals. Chem. Sci., 5(4), 1390-1395. https://doi.org/10.1039/C3SC53432D.

Hering, T., Muhldorf, B., Wolf, R., \& Konig, B. (2016). Halogenase-Inspired Oxidative Chlorination Using Flavin Photocatalysis. Angew. Chem. Int. Ed. Engl., 55(17), 53425345. https://www.ncbi.nlm.nih.gov/pmc/articles/PMC5069574/pdf/ANIE-555342.pdf.

Huvaere, K., Andersen, M. L., Storme, M., Van Bocxlaer, J., Skibsted, L. H., \& De Keukeleire, D. (2006). Flavin-induced photodecomposition of sulfur-containing amino acids is decisive in the formation of beer lightstruck flavor. Photochem. Photobiolo. Sci., 5(10), 961-969. https://doi.org/10.1039/b609337j.

Lee, J. H., \& Min, D. B. (2009). Changes of Headspace Volatiles in Milk with Riboflavin Photosensitization. J. Food Sci., 74(7), C563-C568. https://doi.org/https://doi.org/10.1111/j.1750-3841.2009.01295.x.

Lieberman, M., Kunishi, A. T., Mapson, L. W., \& Wardale, D. A. (1965). Ethylene production from methionine. Biochem. J., 97(2), 449. https://www.ncbi.nlm.nih.gov/pmc/articles/PMC1264661/pdf/biochemj007610136.pdf.

Mattivi, F., Monetti, A., Vrhovšek, U., Tonon, D., \& Andrés-Lacueva, C. (2000). Highperformance liquid chromatographic determination of the riboflavin concentration in white wines for predicting their resistance to light. Journal of Chromatography A, 888(1-2), 121-127. https://doi.org/10.1016/S0021-9673(00)00561-6.

Maujean, A., \& Seguin, N. (1983). Sunstruck flavors in champagne wines. 3. Photochemical reactions responsible for sunstruck flavors in champagne wine. Sci. Aliments, 3(4), 589-601.

Naito, A., Kominami, S., Akasaka, K., \& Hatano, H. (1977). Nature of a cation radical in $\gamma-$ irradiated $\mathrm{N}$-acetyl DL-methionine as disclosed from 33S-hyperfine coupling. Chem. Phys. Lett., 47(1), 171-173. https://doi.org/https://doi.org/10.1016/00092614(77)85332-3.

Reynaud, J. A., Malfoy, B., \& Canesson, P. (1980). Electrochemical investigations of amino acids at solid electrodes. Part I. Sulfur components: cystine, cysteine, methionine. $J$. Electroanal. Chem. Interfacial Electrochem., 114(2), 195-211. https://doi.org/10.1016/0368-1874(80)80375-3.

Vcelakova, K., Zuskova, I., Kenndler, E., \& Gas, B. (2004). Determination of cationic mobilities and pKa values of 22 amino acids by capillary zone electrophoresis. Electrophoresis, 25(2), 309-317. https://doi.org/10.1002/elps.200305751.

Wagner, P. J. (1989). Steady-State Kinetics. In J. C. Scaiano (Ed.), Handbook of Organic Photochemistry. Boca Raton, Florida, USA: CRC Press.

Yang, S. F., Ku, H. S., \& Pratt, H. K. (1967). Photochemical Production of Ethylene from Methionine and Its Analogues in the Presence of Flavin Mononucleotide. J. Biol. Chem., 242(22), 5274-5280. http://www.jbc.org/content/242/22/5274.abstractN2

Yashiro, H., White, R. C., Yurkovskaya, A. V., \& Forbes, M. D. E. (2005). Methionine Radical Cation: Structural Studies as a Function of $\mathrm{pH}$ Using X- and Q-Band TimeResolved Electron Paramagnetic Resonance Spectroscopy. J. Phys. Chem. A, 109(26), 5855-5864. https://doi.org/10.1021/jp051551k.

Zhou, X., Lu, Y., Wang, W., Borhan, B., \& Reid, G. E. (2010). 'Fixed charge' chemical derivatization and data dependant multistage tandem mass spectrometry for mapping 
protein surface residue accessibility. J. Am. Soc. Mass Spectr., 21(8), 1339-1351. https://doi.org/10.1016/j.jasms.2010.03.047.

417

418 

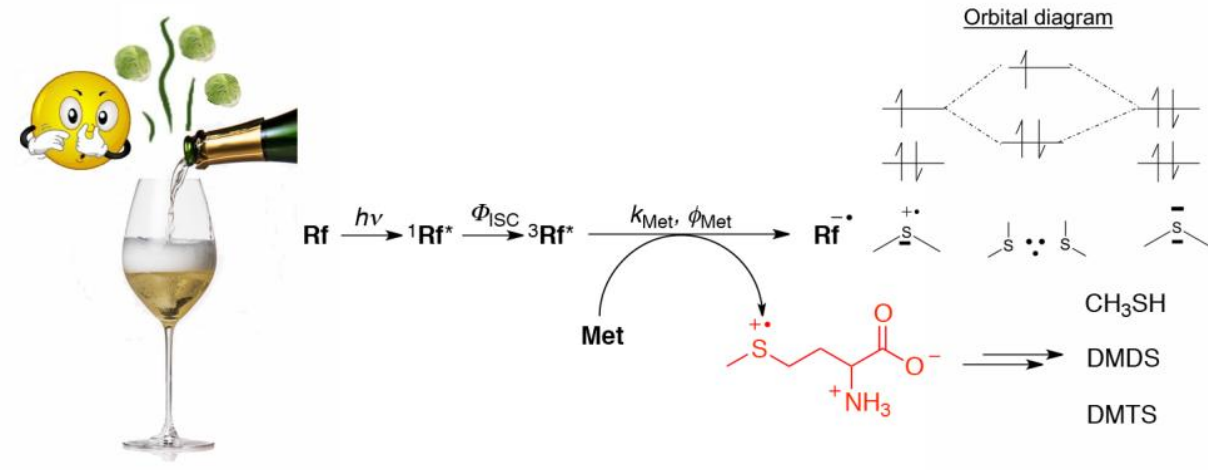